\title{
Spatial Model Specification for Contractual Arrangements between Rural Hospitals and Physicians
}

\section{J. Matthew Fannin and James N. Barnes*}

\begin{abstract}
We test sensitivity of model specification on the choice of contractual physician arrangements by hospitals through use of spatially defined covariates, rural/urban subset models, and geographically weighted regression (GWR) models. Results show that hospitals are significantly influenced by neighboring hospitals' physician arrangement choices whether they are market-oriented or integrated arrangements. Further, some spatial covariates were shown to be nonstationary across space, including variables that were insignificant in the global parameter models. Results suggest health care scholars consider varying parameter models in order to avoid global statements concerning health care relationships and evaluating the performance of health policy.
\end{abstract}

Keywords: hospital-physician contracts, geographically weighted regression, transaction cost theory, varying parameter models

JEL Classifications: I12, R12, R15

\section{INTRODUCTION}

The purpose of this paper is to evaluate the sensitivity to alternative spatial estimators of models of hospitals' contracts for physician services. This issue is important from a modeling as well as a policy perspective. That is, proper spatial model specification in the estimation of contractual arrangements between physicians and hospitals helps to identify those contractual structures that optimally align with the attributes of hospitals in general and rural hospitals in particular. Further, an evaluation of model specification may add more analytical results to the debate about how public policy can best address the delivery of health services in rural areas.

Two key conceptual frameworks in the literature explaining optimal contractual arrangements between hospitals and physicians (market bargaining power hypothesis and transaction cost theory) do not explicitly incorporate space. Hence, we present an alternative argument for understanding the choice of physician arrangements based on geographic proximity. The key hypothesis to be tested is that hospitals that are geographically close in distance prefer to use similar types of contracts with physicians to minimize contracting costs, holding all else constant. Empirically, we use variables that capture the arguments of both conceptual frameworks, but our focus in this paper is to understand how including spatial variables improves our understanding of contracting for physician services in rural and urban areas, including improvements to empirical model fit and implications for understanding.

\footnotetext{
* Fannin and Barnes are Associate Professors in the Department of Agricultural Economics and Agribusiness at the Louisiana State University Agricultural Center. Barnes is also Director of the LSU AgCenter's Delta Rural Development Center in Oak Grove.

Contact author: J. Matthew Fannin, Department of Agricultural Economics and Agribusiness, 101 Agricultural Administration Building, LSU AgCenter, Baton Rouge, LA, 70803.Email: mfannin@agcenter.lsu.edu. 
Rurality/remoteness is typically treated as a relative term conceptually; that is, it is often treated as a residual-what is not urban. A hospital may be considered rural if it is geographically located outside a metropolitan area or in a region falling below a threshold population. A hospital also may be considered remote because it lies over a threshold distance from another hospital. Hospitals and policies created to support certain hospital types (e.g. Critical Access Hospital Program) are typically analyzed separately in rural health policy research, and are at best modeled and analyzed with respect to urban hospital equivalents. Rarely is hypothesis testing/policy analysis performed jointly in such a way as to test whether a separate disjointed approach is appropriate. We apply a geographically weighted regression approach to analyze if larger rural-urban regional issues influence physician service contracting of hospitals and what may be learned from such an approach. In particular, we focus on the sensitivity of the statistical significance of covariates to the choice of model specification. Our findings are consistent with previous studies in health care services research that compare and contrast rural and urban areas; that is, dichotomies do exist. In our research, the choice of a hospital's physician arrangement in rural hospitals is influenced even more heavily by arrangements used by nearby hospitals than is the case of urban hospitals. Likewise, such market characteristics as HMO contracting have less of an impact on the choice of physician arrangements in rural areas as compared to their urban counterparts. However, by allowing for a unique parameter for each covariate at each observation in the geographically weighted regression (GWR) approach, we find that an Eastern U.S. hospital's choice of market physician arrangement is positively influenced by hospitals that are slightly further removed from a reference hospital than is the case in the rest of the country. This suggests potential value of including varying parameter models in health care services research and that they could assist policymakers in avoiding unintended outcomes from "one-size fits all" policies toward rural healthcare supply issues.

The paper proceeds as follows. First, we briefly review the history behind creating modern definitions of rural for purposes of health care service delivery. In addition, we review the existing literature modeling space in rural health care delivery. Second, we evaluate alternative spatial models including the spatial lag model, spatial error model, and geographically weighted regression models. Next, we present an empirical model and results from a sensitivity analysis of applying alternative spatial model specifications to the contractual arrangement between physicians and hospitals. We conclude with implications of this analysis on future spatial modeling in rural health research.

\section{LITERATURE REVIEW}

\subsection{Defining Rural for Health Care Policy}

The plight of rural hospitals and the procurement and delivery of health care services to rural areas has been a part of federal policy debate for several decades. Much of the present-day debate about rural hospital funding has been driven by the Critical Access Hospital (CAH) program, a part of the Medicare Rural Hospital Flexibility Program of 1997 (Flex Program) (Dalton et al., 2003; Rural Health Resource Center, 2008). Between the Tax Equity and Fiscal Responsibility Act of 1982 and the initiation of the Flex Program, many rural hospitals were paid reimbursement rates for medical procedures through the Center for Medicare and Medicaid System's Prospective Payment System (PPS) that did not regularly cover the average costs for administering these procedures in rural hospital settings.

(C) Southern Regional Science Association 2010. 
As a result, in much of the 1980s and 1990s, the financial condition of many rural hospitals began to suffer and many were forced to shut their doors (Holmes, Pink and Slifkin, 2006). Fewer privately insured (and more profitable) residents remained in rural areas leaving many rural hospitals having a disproportionately higher share of less profitable Medicare patients from an increasingly older rural population.

These concerns were addressed with the CAH program (Dalton et al.; Rural Health Resource Center). The program pays cost-based-plus reimbursement to hospitals that are eligible for the program. To be eligible, certain "critical access" rules apply. For example, the hospital must be no closer than 35 miles to the nearest hospital (15-mile threshold in mountainous terrain). It must be an in-patient acute care hospital providing 24-hour, 7-days-a-week emergency care. The hospital must have no more than 25 beds (excluding swing-beds for long-term care), and it may only keep a patient admitted for no more than 96 hours before transferring them to a non-CAH hospital.

One of the challenges of CAH and other government policies meant to sustain health care in rural areas has been to effectively define what is "rural" in order to effectively target these policies. Regional scientists such as Isserman (2005) have helped to move the debate along with new classification systems that identify varying degrees of rurality. However, more important than rural classification systems is the application of various measures of rurality and space to health-care procurement and delivery as well as how rural residents access these services. The next section focuses on a dimension of the rural health care services literature that explicitly incorporates space and measures of rurality in its research - spatial markets for rural hospitals.

\subsection{Spatial Specification in Rural Health Care Research}

At present, the dominant area where space has been modeled in the rural health system has been in understanding spatial markets for rural hospitals. Gresenz, Rogowski, and Escarce (2004) analyze hospital, health market, and demographic characteristics that influence the spatial hospital market. In their study, they include spatial right-hand-side competition variables that identify the number of hospitals within 15 and 30 miles of a reference hospital. They estimate separate regressions for rural and urban hospitals and identify which characteristics lead to increases in the distance capturing 75 and 90 percent of all hospital admissions. Tai, Porell, and Adams (2004) estimate hospital choice among rural Medicare beneficiaries. Similar to Gresenz, Rogowski, and Escarce, their dependent variable varies hospitals' spatial typology (closest rural hospital, other rural hospital, urban non-teaching and urban teaching hospitals) as well as including beneficiaries' distances to viable hospital alternatives. Basu and Mobley (2007) evaluate the propensity of the elderly to travel beyond a threshold distance based on severity of illness. In the study, the authors separate the dependent variable (odds of distant versus location admission) based on classifications of rural from rural-urban continuum codes.

In each of these studies, we see a set of common spatial strategies. That is, there is an assumption that heterogeneity exists in the parameters across the rural-urban continuum as per LeSage (2009), or

$$
y_{i}=X_{i} \beta_{j}+\varepsilon_{i}
$$

where

$i$ is $1, \ldots, n$ points in space, $j$ is $1, \ldots, m$ urban/rural regional classifications, $X_{i}$ is a $1 \times k$ vector of explanatory variables for each $i$,

(C) Southern Regional Science Association 2010. 
$\beta_{j}$ is a parameter vector for each $j$, and

$\varepsilon_{i}$ is a stochastic disturbance term for each $i$.

In the previous rural health research examples, $\beta_{j}$ is represented by two or more vectors of parameter estimates based on varying degrees of urban/rural. Further, spatially defined righthand-side variables are often added to more explicitly articulate the role that space has in explaining the variation between the independent and dependent variable.

A trap some social scientists applying spatial econometric models can easily fall into is putting the spatial econometric tool ahead of spatial specification in theory. For example, a researcher may casually apply the spatial autoregressive (SAR) model without any theory explicitly arguing why a spatially lagged dependent variable should explain any variation in the dependent variable. This trap is akin to relying on such statistical tests as a Box-Cox test to identify a "best" functional form for the data used when economic theory and previous research clearly dictate the use of a specific functional form in analysis.

In the same vein, Ali, Partridge, and Olfert (2007) argue that regional scientists have strayed away from their core belief that location matters by applying econometric models that assume a single average response to changes in explanatory variables rather than modeling changing marginal responses across space to changes in explanatory variables. For example, they point out that in a regional growth model a variable can generate both offsetting agglomeration effects as well as congestion effects that result in the variable being insignificant in a global parameter model. Thus, in a varying parameter model such as geographically weighted regression (GWR), such a variable could be positively significant for one region, suggesting stronger agglomeration effects, and negatively significant in another region, suggesting stronger congestion effects.

A wedding of the strengths of both health-care services research and regional science research would be an ideal strategy in model specification and for testing theories as well as evaluating policy in health-care services research. That is, rural health-care services research should allow heterogeneous parameter estimates (based on alternative measures of rurality), apply spatially distinct explanatory policy variables, and incorporate spatial econometric techniques to estimate efficiency. We apply these approaches in the upcoming empirical section to the decision of hospitals to contract for physician services.

\subsection{Hospital Physician Contracting}

The contractual arrangement between hospital and physician has been well-studied over the past 20 years (cf. Mick, 1990; Coles and Hesterly, 1998; Robinson, 1999; Stensland and Stinson, 2002). Much of this literature empirically analyzes how the widespread adoption of managed care contracting has impacted the access, procurement, and quality delivery of health care services, but very little of it has strong underlying conceptual frameworks. The few key exceptions include Cuellar and Gertler (2006), who apply the market bargaining-power hypothesis, and Esposto (2004), Barnes and Fannin (2006) and Fannin and Barnes (2007) who use transaction cost theory.

We argue that none of the applications above evaluate how space either strengthens or weakens the studied relationships, other than a simple rural-urban bifurcation based on a dummy variable in model specifications. The market bargaining-power hypothesis argues that hospitals develop integrated contractual arrangements with physicians in order to obtain a greater stream 
of revenues through exclusive admittance arrangements with physicians. Transaction cost theory predicts that hospitals with lower coordination costs (ex-ante contract development) and motivation costs (ex-post contract enforcement) choose market-based arrangements with physicians if coordination and motivation costs are relatively low and integrated arrangements with physicians if coordination and motivation costs are relatively high. From our review of these two theories, neither the market bargaining-power hypothesis nor the transaction cost theory (at least in its widely interpreted form) has anything to say about how space affects the choice of contract. Nonetheless, we emphatically argue that space does matter in the choice of physician arrangement. In particular, the familiarity or similarity with a specific physician arrangement is impacted by both time and space. That is, a hospital administrator would prefer to use similar contracts with physicians to gain efficiencies afforded by writing and enforcing similar contractual terms. Hence, similarity of contracts is positively related to integration (Barnes, et al. 2004). We argue one way to test this is to focus on the role of location when examining contractual choice by hospitals when procuring physician labor.

Let us provide some examples. If a hospital has five physicians where the physician arrangement chosen is one where the hospital employs physicians full-time while providing the physical plant and equipment for their clinic(s), then there would be a lower cost to the hospital of employing a new, sixth, physician using the same contract. This is because the hospital has already sunk fixed costs into developing the language of the contract and is familiar with the performance measurements and ways it can/must enforce the contract's clauses given its experience with the previous five physicians. This reduces the hospital's uncertainty. A physician can also reduce his/her uncertainty by discussing the nature of the contractual arrangements with the existing physicians to better understand the compensation and practical performance reviews that he/she would entail. Using an alternative contractual vehicle might increase uncertainty to the physician, which might result in additional amendments to the contract, potentially increasing transactions cost as well as uncertainty of future financial strain to the hospital.

In the same way, distance may impact coordination and motivation costs when organizing physician services in hospitals. For example, a coordination cost might involve the hospital's cost of constructing a legal document outlining the physician arrangement as well as the time costs of negotiating acceptable language in the agreement between hospital and physician. A motivation cost may include both the cost of monitoring the performance of a physician in order to ensure that he/she meets stipulations of the arrangement as well as any enforcement costs of litigation. A hospital may benefit by aligning its physician arrangements similarly to those of other hospitals nearby. Hospital administrators can share their experiences of coordinating and motivating specific types of contractual arrangements with physicians, thereby reducing uncertainty and lowering costs. Further, physicians might be able to increase their patient caseload by admitting more of his/her patients to each patient's preferred hospital. The risk to the doctor of such hospital diversification of patients is likely to be lower if she/he can negotiate a similar contractual arrangement with the added hospitals.

Since, like other commuters, doctors tend prefer not to travel far to do their work, each of these examples suggests that hospitals would attempt to align their physician arrangements with those of nearby hospitals and that similarities would diminish with hospitals that are further removed. Hence, the working hypothesis to be tested in this paper is the following: hospitals that 
are geographically close in distance prefer to use similar types of contracts with physicians to minimize contracting costs, holding all else constant. We test this in the next section.

\section{METHODS AND DATA}

An objective of this paper is to perform a comparative analysis of alternative spatial estimators. We begin by estimating a standard logit model for organizational arrangements based on transaction cost theory, the market-bargaining power hypothesis, and other controls. We then evaluate the heterogeneity of these parameter estimates to metropolitan and non-metropolitan area definitions. Next, we evaluate spatial lags in a conventional regression framework by adding variables for hospitals with like physician arrangements within various proximities to the reference hospital both for the full model and for the separate metro and nonmetro subsets.

Finally, we evaluate the heterogeneity of these parameter estimates by estimating a geographically weighted regression (GWR) model (Fotheringham, Brundson, and Charlton, 2002; Ali, Partridge, and Olfert, 2007). GWR models allow for the estimation of individual parameter estimates based on the following equation for a continuous dependent variable regression model:

$$
\begin{aligned}
& y_{i}=\beta_{0}+\beta_{i 1} x_{i 1}+\beta_{i 2} x_{i 2}+\ldots+\beta_{i k} X_{i k}+\varepsilon_{i} ; \varepsilon_{i} \sim N\left(0, \sigma^{2}\right) \\
& i=1,2, \ldots, N ; k=1,2, \ldots, K
\end{aligned}
$$

where there are $\mathrm{n}$ observations and $\mathrm{k}$ explanatory variables. The GWR model estimates individual coefficient estimates for each observation based on the construction of a unique spatial weight matrix, $W_{i}$, based on a subset of nearby observations through the following equation:

$$
\hat{\beta}_{i}=\left(X^{\top} W_{i} X\right)^{-1} X^{\top} W_{i} Y ; i=1,2, \ldots N
$$

where $X$ is an $n \times k$ matrix of explanatory variables, $Y$ is the vector of the dependent variable, and $W_{i}$ is a diagonal matrix of the weights vector of all observations related to $i$.

The spatial weight matrix shows the strengths of the interconnections between observation $i$ and any of its $j$ observation neighbors. The strength of its connection decays as the distance between observation $i$ and $j$ increases.

Likewise, the maximum number of nearby neighbor observations considered to be connected to observation $i$ is defined as the bandwidth (Fotheringham, Brunsdon, and Charlton, 2002). The bandwidth is considered either the total number of observations within a given geographic distance from observation $i$ (which can vary from one observation to the next), or a fixed number of observations that creates heterogeneity in the geographic reach of neighbors from observation to observation. Distance-based bandwidths are better for regular grid data, but a fixed observation bandwidth typically works better for data that are scattered across regions with few nearby neighbors. The optimal bandwidth (distance or numbers of nearest neighbors) is typically estimated through minimization of a cross-validation score or Akaike Information Criterion (AIC) value (Fotheringham, Brunsdon, and Charlton, 2002). The optimal distance or number of nearest neighbors is then applied to each of the $\mathrm{n}$ regressions.

(C) Southern Regional Science Association 2010. 
In our regressions, the dependent variable is binary; that is, whether or not the hospital participates in a market/integrated arrangement or not. In this case, we apply a binary logit GWR as defined by Charlton, Fotheringham, and Brunsdon (2003):

$$
y_{i}^{*}=\frac{e^{\left(\beta_{0}+\beta_{1} x_{1 i}+\ldots+\beta_{k} x_{k i}\right)}}{1+e^{\left(\beta_{0}+\beta_{1} x_{1 i}+\ldots+\beta_{k} x_{k i}\right)}},
$$

where

$y_{i}^{*}$ is the predicted value of $y_{i}$. Further, as

$e^{\left(\beta_{0}+\beta_{1} x_{1 i}+\ldots+\beta_{k} x_{k i}\right)} \rightarrow 0$, then $y_{i}^{*} \rightarrow 0$, and as

$e^{\left(\beta_{0}+\beta_{1} x_{i i}+\ldots+\beta_{k} x_{k i}\right)} \rightarrow \infty$, then $y_{i}^{*} \rightarrow 1$, which results in

$$
1-y_{i}^{*}=\frac{1}{1+e^{\left(\beta_{0}+\beta_{1} x_{1 i}+\ldots+\beta_{k} x_{k i}\right)}}, \text { thus }
$$$$
\frac{y_{i}^{*}}{1-y_{i}^{*}}=e^{\left(\beta_{0}+\beta_{1} x_{1 i}+\ldots+\beta_{k} x_{k i}\right)}, \text { and }
$$

$$
\ln \left(\frac{y_{i}^{*}}{1-y_{i}^{*}}\right)=\beta_{0}+\beta_{1} x_{1 i}+\ldots+\beta_{k} x_{k i} .
$$

An iterative least squares procedure is then used to calibrate the model and obtain estimates (Charlton, Fotheringham, and Brunsdon, 2003). In addition, an informal test for nonstationary (heterogeneous) parameter estimates by Charlton, Fotheringham and Brunsdon can be performed. The interquartile range of the GWR parameter estimates from Equation 7 can be calculated (the difference between the $75^{\text {th }}$ and $25^{\text {th }}$ quartile parameter estimates) and compared to the global (full model) standard errors for each parameter. If the interquartile range is greater than two times the standard error in the global (full sample) logit model, then nonstationarity may exist in the parameter.

The data for these regressions come from the 2004 American Hospital Association Annual Survey Database (American Hospital Association, 2006) and the Area Resource File 2006 (Quality Resource Systems, 2007). The dependent variables in the model are market and integrated. The market arrangement (npho) refers to hospitals that identified as having no physician arrangement, an Independent Practice Association (IPA) arrangement, a Group Practice Without Walls (GPWW) arrangement, an Open Physician-Hospital Organization (OPHO) arrangement only or a combination of these four only. These arrangements were considered to have similar arrangement structures that would be classified on the market side of the arrangement continuum. Likewise the integrated arrangement (emhy) included hospitals having a Closed Physician-Hospital Organization (CPHO), Management Service Organization (MSO), Integrated Salary Model (ISM), Equity Model, a Foundation model arrangement or a combination of the five only. A complete description of each of the detailed physician arrangements is provided in the Appendix.

A number of explanatory variables are included. Hmo refers to a hospital that has one or more Health Maintenance Organization contracts and is expected to increase the probability that a hospital will enter into an integrated contractual arrangement with a physician. Pltpadm refers to the property, plant and equipment to total admissions ratio. As pltpadm increases, the cost of

(C) Southern Regional Science Association 2010. 
coordinating physician arrangements and monitoring physician effort increase for the hospital thereby increasing the probability that the hospital will enter into an integrated arrangement with physicians.

The main spatial explanatory variables include nphop15, nphop315, nphop350, and npho510 which represent the percentage of hospitals with market arrangements only within 15 miles, between 15 and 35 miles, between 35 and 50 miles and between 50 and 100 miles respectively; and emhyp15, emhyp315, emhyp350, and emhyp510 with integrated arrangements only within 15 miles, between 15 and 35 miles, between 35 and 50 miles and between 50 and 100 miles, respectively. As stated earlier, we expect that as distance decreases for a given percentage of nearby hospitals with a given physician arrangement (either market or integrated), the probability that these hospitals will take on the same hospital physician arrangement of their hospital neighbors increases.

The remaining variables are controls for hospital and demographic characteristics. Pc_mcare is the percentage of total inpatient days accrued to Medicare patients; $p c \_$mcaid includes the percentage of total inpatient days accrued to Medicaid patients; netwrk is a dummy variable referring to whether or not the hospital is part of a larger health care network; netw_15, netw_315, and netw_350 refer to the number of hospitals within 15 miles, between 15 and 35 miles, and between 35 and 50 miles that are included in the same network as the dependent variable hospital; beds is the total number of beds in the hospital; profit is a dummy variable for whether or not the hospital is for-profit; mhi is the median household income of the hospital's county of residence, and popsqmi is the population per square mile of the hospital's county of residence.

Data were collected for all hospitals that completed questions that applied to variables in the analysis. A total of 3,509 hospitals were included in the full model. All data were for 2004.

\section{RESULTS}

Descriptive statistics of the variables in the model are presented in Table $1 .^{1}$ As can be seen, approximately 60 percent and 30 percent of hospitals in the dataset have market-oriented and integrated-oriented arrangements with their physicians, respectively. Since a hospital responding to the AHA survey could choose any physician arrangement where it had at least one physician classified as having that arrangement with the hospital, then some hospitals had a combination of physicians with arrangements that were categorized in both market and integrated arrangement categories. This constituted approximately 10 percent of all hospitals. Approximately 70 percent of the hospitals contract with one or more HMOs and almost half the inpatients days in the 2004 calendar year for the hospitals in the dataset were consumed by Medicare patients.

\footnotetext{
${ }^{1}$ The "shares" in the descriptive statistics applied in the logit regressions are interpreted as percentages in the remainder of the manuscript.
}

(C) Southern Regional Science Association 2010. 
Table 1. Descriptive Statistics for Full Model

\begin{tabular}{|c|c|c|c|c|c|}
\hline Variables & 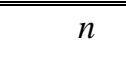 & Mean & S.D. & Min & $\overline{\mathrm{Max}}$ \\
\hline Market arrangement (npho) & 3,509 & 0.597 & 0.491 & 0 & 1 \\
\hline Integrated arrangement (emhy) & 3,509 & 0.308 & 0.462 & 0 & 1 \\
\hline \multicolumn{6}{|l|}{ Neighboring Hospitals with Market Arrangements } \\
\hline Share less than $15 \mathrm{mi}$ (nphop15) & 3,509 & 0.542 & 0.352 & 0 & 1 \\
\hline Share between $15 \mathrm{mi}$ and $35 \mathrm{mi} \mathrm{(nphop315)}$ & 3,509 & 0.525 & 0.267 & 0 & 1 \\
\hline Share between $35 \mathrm{mi}$ and $50 \mathrm{mi}$ (nphop350) & 3,509 & 0.52 & 0.242 & 0 & 1 \\
\hline Share between $50 \mathrm{mi}$ and $100 \mathrm{mi}$ (nphop510) & 3,509 & 0.513 & 0.143 & 0 & 1 \\
\hline \multicolumn{6}{|l|}{ Neighboring Hospitals with Integrated Arrangements } \\
\hline Share less than $15 \mathrm{mi}$ (emhyp15) & 3,509 & 0.271 & 0.328 & 0 & 1 \\
\hline Share between $15 \mathrm{mi}$ and $35 \mathrm{mi}$ (emhyp315) & 3,509 & 0.238 & 0.222 & 0 & 1 \\
\hline Share between $35 \mathrm{mi}$ and $50 \mathrm{mi}$ (emhyp350) & 3,509 & 0.244 & 0.203 & 0 & 1 \\
\hline Share between $50 \mathrm{mi}$ and $100 \mathrm{mi}$ (emhyp510) & 3,509 & 0.248 & 0.114 & 0 & 1 \\
\hline \multicolumn{6}{|l|}{ Network Effects } \\
\hline Hospital in network (netwrk) & 3,509 & 0.381 & 0.486 & 0 & 1 \\
\hline \# of own-network hospitals within 15 mi (netw_15) & 3,509 & 0.126 & 0.638 & 0 & 10 \\
\hline \# of own-network hospitals from 15 - 35 mi (netw_315) & 3,509 & 0.141 & 0.661 & 0 & 12 \\
\hline \# of own-network hospitals from 35 -50 mi (netw_350) & 3,509 & 0.083 & 0.441 & 0 & 7 \\
\hline \multicolumn{6}{|l|}{ Hospital Characteristics } \\
\hline Hospital Participates in HMO $(\mathrm{hmo})$ & 3,509 & 0.698 & 0.459 & 0 & 1 \\
\hline \# of beds (beds) & 3,509 & 171.9 & 185.9 & 2 & 2,095 \\
\hline Share of admissions that are Medicare ( $p c \_$mcare) & 3,509 & 0.486 & 0.24 & 0 & 1 \\
\hline Share of admissions that are Medicaid ( $p c \_$mcaid) & 3,509 & 0.182 & 0.186 & 0 & 1 \\
\hline Plant and equipment cost per admission (pltpadm) & 3,509 & $\$ 24,456$ & $\$ 383,044$ & & $\$ 22,500,000$ \\
\hline For-profit Hospital (profit) & 3,509 & 0.14 & 0.347 & 0 & 1 \\
\hline \multicolumn{6}{|l|}{ Demographic Characteristics } \\
\hline Median household income (mhi) & 3,509 & $\$ 41,919$ & $\$ 10,247$ & $\$ 19,090$ & $\$ 87,701$ \\
\hline Population per square mile (popsqmi) & 3,509 & $1,238.3$ & $4,766.1$ & 0.9 & $68,062.8$ \\
\hline
\end{tabular}

\subsection{Explanatory Spatial Variables}

Table 2 reports regression results from the base model and full model (with spatial variables identifying nearby hospitals with similar arrangements) using a traditional aspatial logit regression. As can be seen, a number of relationships can be determined. First, from the base model, we see several significant relationships. In the market equation, a hospital that participates in a network or an HMO is less likely to choose a market arrangement with a physician. Similarly, as the number of beds increase, the hospital is also less likely to choose a market arrangement with a physician. Hospitals that have a large percentage of Medicare admissions, are for-profit entities, and are located in counties with higher population densities are more likely to choose a market-based arrangement. Analogously, hospitals that are part of a network and participate in at least one HMO are more likely to choose an integrated arrangement with physicians. Higher median household incomes and population densities of the counties in 


\section{Table 2. Comparison of Logit Model Results on Market and Integrated Contractual Arrangement Equations: Base versus Full Model}

\begin{tabular}{|c|c|c|c|c|}
\hline \multirow[b]{2}{*}{ Variables } & \multicolumn{2}{|r|}{ Market } & \multicolumn{2}{|c|}{ Integrated } \\
\hline & Full & Base & Full & Base \\
\hline \multicolumn{5}{|c|}{ Neighboring Hospitals with Integrated Arrangements } \\
\hline \multirow[t]{3}{*}{ nphop15 (M)/emphyp15 (I) } & 7.324 & & 8.247 & \\
\hline & $(0.211)^{* * *}$ & & $(0.267)^{* * *}$ & \\
\hline & {$[1.544]$} & & {$[1.458]$} & \\
\hline \multirow[t]{3}{*}{ nphop315 (M)/emhyp315 (I) } & -0.042 & & 0.008 & \\
\hline & -0.228 & & -0.297 & \\
\hline & {$[-0.009]$} & & {$[0.001]$} & \\
\hline \multirow[t]{3}{*}{ nphop350 (M)/emhyp350 (I) } & -0.508 & & -0.167 & \\
\hline & $(0.246)^{* *}$ & & -0.325 & \\
\hline & {$[-0.107]$} & & {$[-0.029]$} & \\
\hline \multirow[t]{3}{*}{ nphop510 (M)/emhyp510 (I) } & -1.683 & & -1.289 & \\
\hline & $(0.420)^{* * *}$ & & $(0.598)^{* *}$ & \\
\hline & {$[-0.355]$} & & {$[-0.228]$} & \\
\hline \multicolumn{5}{|l|}{ Network Effects } \\
\hline \multirow[t]{3}{*}{ netwrk } & -0.233 & -0.271 & 0.231 & 0.146 \\
\hline & $(0.114)^{* *}$ & $(0.078)^{* * *}$ & $(0.125)^{*}$ & $(0.082)^{*}$ \\
\hline & {$[-0.050]$} & {$[-0.065]$} & {$[0.041]$} & {$[0.031]$} \\
\hline \multirow[t]{3}{*}{ netw_15 } & -0.103 & 0.019 & 0.022 & -0.077 \\
\hline & -0.075 & -0.063 & -0.081 & -0.077 \\
\hline & {$[-0.022]$} & {$[0.005]$} & {$[0.004]$} & {$[-0.016]$} \\
\hline \multirow[t]{3}{*}{ netw_315 } & 0.158 & 0.088 & -0.086 & -0.036 \\
\hline & -0.1 & -0.068 & -0.096 & -0.069 \\
\hline & {$[-0.022]$} & {$[0.021]$} & {$[-0.015]$} & {$[-0.008]$} \\
\hline \multirow[t]{3}{*}{ netw_350 } & 0.174 & 0.156 & -0.042 & -0.11 \\
\hline & -0.12 & $(0.094)^{*}$ & -0.157 & -0.102 \\
\hline & {$[0.037]$} & {$[0.037]$} & {$[-0.007]$} & {$[-0.023]$} \\
\hline \multicolumn{5}{|l|}{ Hospital Characteristics } \\
\hline \multirow[t]{3}{*}{ hmo } & -0.364 & -0.333 & 0.426 & 0.272 \\
\hline & $(0.126)^{* * *}$ & $(0.084)^{* * *}$ & $(0.143)^{* * *}$ & $(0.089)^{* * *}$ \\
\hline & {$[-0.074]$} & {$[-0.078]$} & {$[0.072]$} & {$[0.056]$} \\
\hline \multirow[t]{3}{*}{ beds } & $-1.28 \mathrm{E}-03$ & $-1.20 \mathrm{E}-03$ & $1.31 \mathrm{E}-03$ & $3.17 \mathrm{E}-04$ \\
\hline & $(2.92 \mathrm{E}-04)^{* * *}$ & $(2.19 \mathrm{E}-04)^{* * *}$ & $(2.70 \mathrm{E}-04)^{* * *}$ & $-2.14 \mathrm{E}-04$ \\
\hline & {$[-2.71 \mathrm{E}-04]$} & {$[-2.87 \mathrm{E}-04]$} & {$[2.32 \mathrm{E}-04]$} & {$[6.66 \mathrm{E}-05]$} \\
\hline \multirow[t]{2}{*}{ pc_mcare } & $\begin{array}{r}1.399 \\
(0287)^{* * * *}\end{array}$ & $\begin{array}{r}0.822 \\
(0191)^{* * *}\end{array}$ & $\begin{array}{r}-2.424 \\
(0.290) * * *\end{array}$ & $\begin{array}{r}-1.282 \\
(0.199)^{* * *}\end{array}$ \\
\hline & $\begin{array}{r}(0.287)^{* * *} \\
{[0.295]}\end{array}$ & $\begin{array}{r}(0.191)^{* * *} \\
{[0.197]}\end{array}$ & $\begin{array}{r}(0.290)^{* * *} \\
{[-0.429]}\end{array}$ & $\begin{array}{r}(0.199) \\
{[-0.270]}\end{array}$ \\
\hline
\end{tabular}

(C) Southern Regional Science Association 2010. 


\begin{tabular}{|c|c|c|c|c|}
\hline \multirow[b]{2}{*}{ Variables } & \multicolumn{2}{|r|}{ Market } & \multicolumn{2}{|r|}{ Integrated } \\
\hline & Full & Base & Full & Base \\
\hline \multirow[t]{3}{*}{ pc_mcaid } & 0.224 & 0.118 & -0.754 & -0.403 \\
\hline & -0.338 & -0.237 & $(0.359)^{* *}$ & $(0.240)^{*}$ \\
\hline & {$[0.047]$} & {$[0.028]$} & {$[-0.133]$} & {$[-0.085]$} \\
\hline \multirow[t]{3}{*}{ pltpadm } & $-9.06 \mathrm{E}-07$ & $-1.07 \mathrm{E}-06$ & $6.30 \mathrm{E}-07$ & $1.65 \mathrm{E}-06$ \\
\hline & $-6.65 \mathrm{E}-07$ & $-1.38 \mathrm{E}-06$ & $-8.79 \mathrm{E}-07$ & $-1.84 \mathrm{E}-06$ \\
\hline & {$[-1.91 \mathrm{E}-07]$} & {$[-2.56 \mathrm{E}-07]$} & [1.11E-07] & [3.46E-07] \\
\hline \multirow[t]{2}{*}{ profit } & $\begin{array}{r}0.928 \\
(0.159)^{* * *}\end{array}$ & $\begin{array}{r}1.008 \\
(0.121)^{* * *}\end{array}$ & $\begin{array}{r}-0.601 \\
(0.178)^{* * *}\end{array}$ & $\begin{array}{r}-0.862 \\
(0.131)^{* * *}\end{array}$ \\
\hline & {$[0.167]$} & {$[0.215]$} & {$[-0.094]$} & {$[-0.157]$} \\
\hline \multicolumn{5}{|c|}{ Demographic Characteristics } \\
\hline \multirow[t]{3}{*}{ popsqmi } & $3.89 \mathrm{E}-05$ & $2.86 \mathrm{E}-05$ & $-5.99 \mathrm{E}-06$ & $-2.81 \mathrm{E}-05$ \\
\hline & $(1.08 \mathrm{E}-05)^{* * *}$ & $(8.74 \mathrm{E}-06)^{* * *}$ & $-9.52 \mathrm{E}-06$ & $(8.26 \mathrm{E}-06)^{* * *}$ \\
\hline & {$[8.20 \mathrm{E}-06]$} & {$[6.85 \mathrm{E}-06]$} & {$[-1.06 \mathrm{E}-06]$} & {$[-5.91 \mathrm{E}-06]$} \\
\hline \multirow[t]{3}{*}{ mhi } & $1.43 \mathrm{E}-05$ & 5.19E-06 & $-6.35 \mathrm{E}-08$ & $-1.24 \mathrm{E}-05$ \\
\hline & $(5.35 \mathrm{E}-06)^{* * *}$ & $-3.75 \mathrm{E}-06$ & $-5.76 \mathrm{E}-06$ & $(4.09 \mathrm{E}-06) * * *$ \\
\hline & {$[3.02 \mathrm{E}-06]$} & {$[1.24 \mathrm{E}-06]$} & {$[-1.12 \mathrm{E}-08]$} & {$[-2.61 \mathrm{E}-06]$} \\
\hline \multirow[t]{2}{*}{ Constant } & -2.924 & 0.143 & -2.294 & 0.212 \\
\hline & $(0.398)^{* * *}$ & -0.217 & $(0.354)^{* * *}$ & -0.227 \\
\hline \multicolumn{5}{|l|}{ Diagnostics } \\
\hline$n$ & 3,509 & 3,509 & 3,509 & 3,509 \\
\hline Wald $\chi^{2}$ & $1,355.04$ & 192.51 & $1,023.79$ & 132.94 \\
\hline LM-Lag & & $61.18 * * *$ & & $47.65 * * *$ \\
\hline LM-Error & & $60.59 * * *$ & & $44.05 * * *$ \\
\hline Predicted Probability & 0.698 & 0.603 & 0.229 & 0.301 \\
\hline
\end{tabular}

Notes: Standard errors are in parenthesis. Marginal effects are in brackets. $* * *, * *, *$ represent significant values at $1 \%$, $5 \%$, and $10 \%$, respectively.

which the hospital resides significantly decrease the probability that a hospital will choose an integrated arrangement with a physician. Also, hospitals with higher percentages of Medicare and Medicaid admissions are statistically less likely to choose an integrated arrangement with a physician.

The HMO variable (market bargaining power hypothesis) was significant and positive for the integrated arrangement and negative and significant with the market arrangement. The property, plant and equipment cost per admission (transaction cost theory proxy) was insignificant in both equations. ${ }^{2}$

The dummy variable netwrk was significantly positive in the integrated equation and significantly negative in the market equation. The additional spatial variables identifying the number of hospitals of the same network had no strong significant influence on the hospital

\footnotetext{
${ }^{2}$ We tried alternative proxies for transaction cost theory such as the case mix index (a proxy for the complexity of the transaction) used by Esposto (2004) with no statistical significance found.
}

Southern Regional Science Association 2010. 
arrangement chosen. It could be argued that hospitals that are part of the same network within geographic proximity may be serving different missions (general acute care hospital, critical access hospital, surgical hospital) and their missions may dictate alternative arrangement choices. However, even after controlling for local network hospitals, a hospital that is part of a network will more likely choose integrated arrangements with physicians.

Before we proceed with a complete discussion of the full model, we first tested the base model for presence of spatial correlation in the dependent variable (LM-lag) and spatial correlation in the residuals (LM-error). We followed a classical approach to spatial dependence testing as outlined by Florax, Fulmer, and Rey (2003). We applied LM tests for both the market and integrated equations. In both cases, LM tests for presence of spatial dependence in both the dependent variable and the disturbance term were significant. As suggested by the classical approach, we chose to apply a spatial lag modeling structure since the LM-lag value exceeded the LM-error value in both equations. As an alternative to the traditional spatial lag variable, rho, we disaggregated the spatially dependent variable into five spatial explanatory variables as discussed previously. A discussion of their results in the context of the full model is presented below.

When we add the spatial variables to the non-spatial logit regression in the full model, we see a number of additional relationships. For both the market and integrated equations, we see that a hospital is more likely to use the same type of physician arrangement of other nearby hospitals within 15 miles. Analogously, we see hospitals are statistically less likely to take on the same physician arrangement of hospitals 35 to 50 miles away (at least for the market arrangement) and 50 to 100 miles (for both market and integrated). This finding is consistent with our original hypothesis: hospitals that are closer together geographically are more likely to choose similar physician arrangements, other factors constant. A closer review of the full model shows how much physician arrangements of nearby hospitals influence a hospital's choice of arrangement. The marginal effect in the market equation for the percentage of hospitals within 15 miles with the same physician arrangement was 1.544 . This means that for a one-percent increase in the percentage of hospitals within 15 miles of a reference hospital with a market physician arrangement, the probability that the reference hospital chooses the same arrangement increases 1.54 percent. For hospitals with a small number of hospital neighbors, the probability increases are measurable. For example, let's assume that a hospital has four neighboring hospitals within 15 miles and two of the four hospitals have market physician arrangements. If a third hospital exogenously renegotiates their physician arrangements to only market arrangements, then the probability that the reference hospital will then choose to negotiate only market physician arrangements increases almost 39 percent $(1.544 \times 25$ percent increase $)$, ceteris paribus. The next largest positive marginal effect in the same full model market equation was the percent of total admissions that were Medicare patients at 0.295 . Hence, for a one-percent increase in Medicare patient admissions, there is a 0.295 percent increase in the probability that the hospital will choose only market arrangements with their physicians. A corresponding 25 percent increase in Medicare admissions (which would push total percentage of Medicare admissions from the mean to almost 74 percent) would increase the probability that a hospital would incur only market arrangements by just over 7 percent, ceteris paribus.

For the market equation, the full model increased predicted probability from 60 percent to 70 percent. This increase in predicted probability was expected given the statistically significant 
Table 3. Comparison of Logit Model Results on Market and Integrated Contractual Arrangement Equations: Metropolitan versus Nonmetropolitan

\begin{tabular}{|c|c|c|c|c|c|c|}
\hline \multirow[b]{2}{*}{ Variables } & \multicolumn{3}{|c|}{ Market } & \multicolumn{3}{|c|}{ Integrated } \\
\hline & Full & Non-Metro & Metro & Full & Non-Metro & Metro \\
\hline \multicolumn{4}{|c|}{ Neighboring Hospitals with Integrated Arrangements } & & & \\
\hline \multirow[t]{3}{*}{ nphop15 (M)/emhyp15 (I) } & 7.324 & 10.602 & 5.938 & 8.247 & 12.141 & 7.126 \\
\hline & $(0.211)^{* * *}$ & $(0.534)^{* * *}$ & $(0.265)^{* * *}$ & $(0.267)^{* * *}$ & $(0.680)^{* * *}$ & $(0.348)^{* * *}$ \\
\hline & [1.544] & {$[1.790]$} & [1.340] & [1.458] & {$[1.544]$} & [1.276] \\
\hline \multirow[t]{3}{*}{ nphop315 (M)/emhyp315 (I) } & -0.042 & -0.173 & 0.102 & 0.008 & 0.97 & 0.105 \\
\hline & -0.228 & -0.536 & -0.272 & -0.297 & -0.789 & -0.358 \\
\hline & {$[-0.009]$} & {$[-0.029]$} & [0.023] & [0.001] & {$[0.123]$} & [0.019] \\
\hline \multirow{3}{*}{ nphop350 (M)/emhyp350 (I) } & -0.508 & -0.22 & -0.355 & -0.167 & -0.178 & -0.128 \\
\hline & $(0.246)^{* *}$ & -0.661 & -0.279 & -0.325 & -0.941 & -0.3633 \\
\hline & {$[-0.107]$} & {$[-0.037]$} & {$[-0.801]$} & {$[-0.029]$} & {$[-0.023]$} & {$[-0.023]$} \\
\hline \multirow[t]{3}{*}{ nphop510 (M)/ emhyp510 (I) } & -1.683 & -0.986 & -1.475 & -1.289 & -2.034 & -0.92 \\
\hline & $(0.420)^{* * *}$ & -1.201 & $(0.462)^{* * *}$ & $(0.598) * *$ & -1.548 & -0.66 \\
\hline & {$[-0.355]$} & {$[-0.166]$} & {$[-0.333]$} & {$[-0.228]$} & {$[-0.259]$} & {$[-0.165]$} \\
\hline \multicolumn{7}{|l|}{ Network Effects } \\
\hline \multirow[t]{3}{*}{ netwrk } & -0.233 & -0.636 & -0.196 & 0.231 & 0.795 & 0.202 \\
\hline & $(0.114)^{* *}$ & $(0.360)^{*}$ & -0.121 & $(0.125)^{*}$ & $(0.406)^{* *}$ & -0.133 \\
\hline & {$[-0.050]$} & {$[-0.112]$} & {$[-0.045]$} & [0.041] & [0.109] & [0.037] \\
\hline \multirow[t]{3}{*}{ netw_15 } & -0.103 & 0.333 & -0.091 & 0.022 & -0.81 & -0.013 \\
\hline & -0.075 & -0.959 & -0.076 & -0.081 & -0.899 & -0.081 \\
\hline & {$[-0.022]$} & {$[0.056]$} & {$[-0.021]$} & [0.004] & {$[-0.103]$} & {$[-0.002]$} \\
\hline \multirow[t]{3}{*}{ netw_315 } & 0.158 & 0.391 & 0.158 & -0.086 & -1.534 & -0.027 \\
\hline & -0.1 & -0.329 & -0.099 & -0.096 & $(0.402)^{* * *}$ & -0.087 \\
\hline & {$[-0.022]$} & {$[0.066]$} & [0.036] & {$[-0.015]$} & {$[-0.195]$} & {$[-0.005]$} \\
\hline \multirow[t]{3}{*}{ netw_350 } & 0.174 & 0.244 & 0.119 & -0.042 & 0.546 & -0.068 \\
\hline & -0.12 & -0.303 & -0.128 & -0.157 & $(0.280)^{* *}$ & -0.174 \\
\hline & {$[0.037]$} & [0.041] & [0.027] & {$[-0.007]$} & {$[0.069]$} & {$[-0.012]$} \\
\hline \multicolumn{7}{|l|}{ Hospital Characteristics } \\
\hline \multirow[t]{3}{*}{ hmo } & -0.364 & -0.466 & -0.406 & 0.426 & 0.219 & 0.347 \\
\hline & $(0.126)^{* * *}$ & -0.309 & $(0.152)^{* * *}$ & $(0.143)^{* * *}$ & -0.338 & $(0.167)^{* *}$ \\
\hline & {$[-0.074]$} & {$[-0.078]$} & {$[-0.088]$} & [0.072] & {$[0.028]$} & {$[0.059]$} \\
\hline \multirow[t]{3}{*}{ beds } & $-1.28 \mathrm{E}-03$ & $3.45 \mathrm{E}-04$ & $-1.38 \mathrm{E}-03$ & $1.31 \mathrm{E}-03$ & $2.40 \mathrm{E}-03$ & $1.01 \mathrm{E}-03$ \\
\hline & $(2.92 \mathrm{E}-04)^{* * *}$ & $-2.07 \mathrm{E}-03$ & $(2.96 \mathrm{E}-04)^{* * *}$ & $(2.70 \mathrm{E}-04) * * *$ & $-2.20 \mathrm{E}-03$ & $67 \mathrm{E}-04)^{* * *}$ \\
\hline & [-2.71E-04] & [5.82E-05] & [-3.12E-04] & {$[2.32 \mathrm{E}-04]$} & {$[3.05 \mathrm{E}-04]$} & [1.81E-04] \\
\hline \multirow[t]{2}{*}{ pc_mcare } & $\begin{array}{r}1.399 \\
(0.287)^{* * *}\end{array}$ & $\begin{array}{r}1.852 \\
(0.786)^{* *}\end{array}$ & $\begin{array}{r}1.353 \\
(0.315)^{* * *}\end{array}$ & $\begin{array}{r}-2.424 \\
(0.290)^{* * *}\end{array}$ & $\begin{array}{r}-1.679 \\
(0.795)^{* *}\end{array}$ & $\begin{array}{r}-2.323 \\
(0.327)^{* * *}\end{array}$ \\
\hline & [0.295] & [0.313] & {$[0.305]$} & [-0.429] & {$[-0.214]$} & {$[-0.416]$} \\
\hline
\end{tabular}

C Southern Regional Science Association 2010. 


\begin{tabular}{lrrr|rrr}
\hline & Market & Integrated & & Market & Integrated & \\
Variables & Full & Non-Metro & Variables & Full Non-Metro & Variables \\
\hline pc_mcaid & 0.224 & 1.961 & -0.158 & -0.754 & -2.342 & -0.227 \\
& -0.338 & $(0.885)^{* *}$ & -0.376 & $(0.359)^{* *}$ & $(0.976)^{* *}$ & -0.39 \\
pltpadm & {$[0.047]$} & {$[0.331]$} & {$[-0.036]$} & {$[-0.133]$} & {$[-0.298]$} & {$[-0.041]$} \\
& $-9.06 \mathrm{E}-07$ & $-1.55 \mathrm{E}-07$ & $-1.68 \mathrm{E}-06$ & $6.30 \mathrm{E}-07$ & $4.75 \mathrm{E}-07$ & $1.67 \mathrm{E}-06$ \\
& $-6.65 \mathrm{E}-07$ & $-1.98 \mathrm{E}-06$ & $-1.32 \mathrm{E}-06$ & $-8.79 \mathrm{E}-07$ & $-9.16 \mathrm{E}-07$ & $-2.24 \mathrm{E}-06$ \\
profit & {$[-1.91 \mathrm{E}-07]$} & {$[-2.61 \mathrm{E}-08]$} & {$[-3.79 \mathrm{E}-07]$} & {$[1.11 \mathrm{E}-07]$} & {$[6.04 \mathrm{E}-08]$} & {$[2.99 \mathrm{E}-07]$} \\
& 0.928 & -0.316 & 1.105 & -0.601 & 0.52 & -0.875 \\
& $(0.159)^{* * *}$ & -0.476 & $(0.174)^{* * *}$ & $(0.178)^{* * *}$ & -0.634 & $(0.199)^{* * *}$ \\
Demographic Characteristics & {$[0.167]$} & {$[-0.057]$} & {$[0.215]$} & {$[-0.094]$} & {$[0.077]$} & {$[-0.133]$} \\
popsqmi & & & & & & \\
& $3.89 \mathrm{E}-05$ & $4.47 \mathrm{E}-03$ & $3.83 \mathrm{E}-05$ & $-5.99 \mathrm{E}-06$ & $-4.41 \mathrm{E}-03$ & $-1.38 \mathrm{E}-05$ \\
& $(1.08 \mathrm{E}-05)^{* * *}$ & $-3.06 \mathrm{E}-03$ & $(1.09 \mathrm{E}-05)^{* * *}$ & $-9.52 \mathrm{E}-06$ & $-3.99 \mathrm{E}-03$ & $-9.34 \mathrm{E}-06$ \\
mhi & {$[8.20 \mathrm{E}-06]$} & {$[7.54 \mathrm{E}-04]$} & {$[8.64 \mathrm{E}-06]$} & {$[-1.06 \mathrm{E}-06]$} & {$[-5.61 \mathrm{E}-04]$} & {$[-2.48 \mathrm{E}-06]$} \\
& $1.43 \mathrm{E}-05$ & $1.88 \mathrm{E}-05$ & $8.82 \mathrm{E}-06$ & $-6.35 \mathrm{E}-08$ & $-1.74 \mathrm{E}-05$ & $-6.63 \mathrm{E}-06$ \\
& $(5.35 \mathrm{E}-06)^{* * *}$ & $-2.57 \mathrm{E}-05$ & $-5.61 \mathrm{E}-06$ & $-5.76 \mathrm{E}-06$ & $-3.07 \mathrm{E}-05$ & $-6.25 \mathrm{E}-06$ \\
Constant & {$[3.02 \mathrm{E}-06]$} & {$[3.18 \mathrm{E}-06]$} & {$[1.99 \mathrm{E}-06]$} & {$[-1.12 \mathrm{E}-08][-2.21 \mathrm{E}-06]$} & {$[-1.19 \mathrm{E}-06]$} \\
Diagnostics & -2.924 & -5.943 & -2.103 & -2.294 & -3.666 & -1.685 \\
\# of Observations & $(0.398)^{* * *}$ & $(1.337)^{* * *}$ & $(0.437)^{* * *}$ & $(0.354)^{* * *}(1.303)^{* * *}$ & $(0.395)^{* * *}$ \\
Wald Chi-Square & & & & & & \\
Predicted Probability & 3509 & 1319 & 2190 & 3509 & 1319 & 2190 \\
\hline
\end{tabular}

Notes: Standard errors are in parentheses. Marginal effects are in brackets. ${ }^{* * *},{ }^{* *},{ }^{*}$ represent statistical significance at $1 \%, 5 \%$, and $10 \%$ levels, respectively. $(M)$ denotes the variable is for market equation only. $(I)$ denotes the variable is for integrated equation only.

LM tests in the base model. For the integrated equation, inclusion of the spatial variables actually reduced predicted probability from 30 percent to 23 percent. $^{3}$

\subsection{Metro-Nonmetro Comparison}

In Table 3, we compare the results of the full models from the aspatial logit regression in the market and integrated equations to the estimation of the equations using metropolitan and non-metropolitan subsets. Hospitals were divided into each category based on whether or not the hospital's physical location resided inside a county classified as metropolitan or nonmetropolitan by the census. We do see some divergence in factors impacting the physician arrangement choice by the hospital based on whether they reside in a rural or urban area.

\footnotetext{
${ }^{3}$ This reduction in predicted probability may be due to artificially created heterogeneity in the integrated dependent variable from the aggregation of various physician arrangements that may be less similar than previously assumed. While recent studies such as Cuellar and Gertler (2006) would suggest that aggregation of these variables may be acceptable, earlier work of Dynan et al. (1998) may suggest more dissimilarity. Early sensitivity analysis to alternative aggregations did not reveal any superior alternatives to the ones chosen.
}

(C) Southern Regional Science Association 2010. 
We highlight an example of this relationship with the nphop15 from the market equation. In the integrated equation, we see similarities in major statistical differences between metropolitan and nonmetropolitan counties. In metro counties, hospital participation in an HMO and bed counts statistically increase the probability of integrated physician arrangements, with no effects in nonmetro hospitals. For nonmetro counties, the number of own-network hospitals between 15 and 35 miles and the percent of Medicaid admissions decrease the probability of using integrated physician arrangements, with no statistical impacts from these same variables on metropolitan hospitals.

In both the market and integrated equation subsets, higher prediction probabilities occurred in the nonmetro hospitals. The market equation for nonmetro hospitals correctly predicted the actual physician arrangement 78 percent of the time as compared to only 66 percent of the time for metro hospitals. In the integrated equations, while both metro and nonmetro predicted probabilities were much lower, the metro county hospitals were accurately predicted 23 percent of the time as compared to only 15 percent of the time for nonmetro hospitals.

Table 4. Geographically Weighted Regression Results-Market Equation

\begin{tabular}{|c|c|c|c|c|c|c|c|c|}
\hline Variable & Min & $\begin{array}{l}\text { Lower } \\
\text { Quartile }\end{array}$ & Median & $\begin{array}{c}\text { Upper } \\
\text { Quartile }\end{array}$ & Max & $\begin{array}{c}\text { Inter- } \\
\text { Quartile } \\
\text { Range }\end{array}$ & $\begin{array}{c}2 \mathrm{X} \\
\text { S.E. } \\
\text { Global }\end{array}$ & Result \\
\hline Intercept & -4.257 & -3.812 & -3.574 & -3.258 & -2.518 & 0.554 & 0.796 & Stat. \\
\hline \multicolumn{9}{|c|}{ Neighboring Hospitals with Integrated Arrangements } \\
\hline nphop15 & 6.844 & 7.098 & 7.797 & 8.269 & 8.887 & 1.171 & 0.422 & NonStat. \\
\hline nphop315 & -0.612 & -0.457 & -0.061 & -0.581 & 0.745 & 1.038 & 0.456 & Nonstat. \\
\hline nphop350 & -1.019 & -0.714 & -0.544 & -0.426 & -0.042 & 0.288 & 0.492 & Stat. \\
\hline nphop510 & -2.385 & -1.47 & -1.245 & -0.213 & 0.703 & 1.257 & 0.84 & Nonstat. \\
\hline \multicolumn{9}{|c|}{ Network Effects } \\
\hline netwrk & -0.358 & -0.305 & -0.241 & -0.209 & 0.027 & 0.096 & 0.228 & Stat. \\
\hline netw_15 & -0.492 & -0.099 & -0.055 & -0.013 & 0.098 & 0.085 & 0.15 & Stat. \\
\hline netw_315 & $-2.16 \mathrm{E}-04$ & 0.68 & 0.98 & 0.244 & 0.628 & 0.176 & 0.2 & Stat. \\
\hline netw_350 & -0.322 & 0.055 & 0.192 & 0.255 & 0.351 & 0.2 & 0.24 & Stat. \\
\hline \multicolumn{9}{|c|}{ Hospital Characteristics } \\
\hline hmo & -0.752 & -0.466 & -0.373 & -0.308 & -0.193 & 0.158 & 0.252 & Stat. \\
\hline beds & $-2.56 \mathrm{E}-03$ & $-2.11 \mathrm{E}-03$ & $-1.53 \mathrm{E}-03$ & $-9.81 \mathrm{E}-04$ & $-7.13 \mathrm{E}-04$ & $1.13 \mathrm{E}-03$ & $5.84 \mathrm{E}-04$ & Nonstat. \\
\hline pc_mcare & 0.518 & 1.045 & 1.179 & 1.627 & 1.868 & 0.582 & 0.574 & Nonstat. \\
\hline pc_mcaid & -0.396 & -0.265 & -0.024 & 0.301 & 1.28 & 0.566 & 0.676 & Stat. \\
\hline pltpadm & $-3.00 \mathrm{E}-06$ & $-1.00 \mathrm{E}-06$ & 0 & 0 & 0 & $1.00 \mathrm{E}-06$ & $1.33 \mathrm{E}-06$ & Stat. \\
\hline profit & 0.596 & 0.709 & 0.77 & 0.836 & 1.123 & 0.128 & 0.318 & Stat. \\
\hline \multicolumn{9}{|c|}{ Demographic Characteristics } \\
\hline$m h i$ & $1.10 \mathrm{E}-05$ & $1.70 \mathrm{E}-05$ & $1.90 \mathrm{E}-05$ & $2.10 \mathrm{E}-05$ & $2.90 \mathrm{E}-05$ & $4.00 \mathrm{E}-06$ & $1.07 \mathrm{E}-05$ & Stat. \\
\hline popsqmi & $-1.90 \mathrm{E}-05$ & $3.50 \mathrm{E}-05$ & 4.80E-05 & $9.60 \mathrm{E}-05$ & $1.22 \mathrm{E}-04$ & $6.10 \mathrm{E}-05$ & $2.16 \mathrm{E}-05$ & Nonstat. \\
\hline
\end{tabular}


Table 5. Geographically Weighted Regression Results-Integrated Equation.

\begin{tabular}{llccccccr}
\hline \hline & & \multicolumn{2}{c}{$\begin{array}{c}\text { Lower } \\
\text { Variables }\end{array}$} & Min & Quartile & Median & $\begin{array}{c}\text { Upper } \\
\text { Quartile }\end{array}$ & \multicolumn{2}{c}{$\begin{array}{c}\text { Inter- } \\
\text { Max }\end{array}$} & $\begin{array}{c}\text { 2X S.E. } \\
\text { Quartile }\end{array}$ & Global & Result \\
\hline Intercept & -3.679 & -2.801 & -2.491 & -2.323 & -1.517 & 0.483 & 0.708 & Stat.
\end{tabular}

Neighboring hospitals with integrated arrangements

$\begin{array}{lrrrrrrrr}\text { emhyp15 } & 7.512 & 7.955 & 8.937 & 9.295 & 9.53 & 1.34 & 0.534 & \text { Nonstat. } \\ \text { emhyp315 } & -0.256 & 0.099 & 0.195 & 0.288 & 0.42 & 0.189 & 0.594 & \text { Stat. } \\ \text { emhyp350 } & -0.756 & -0.329 & -0.205 & -0.121 & 0.493 & 0.208 & 0.65 & \text { Stat. } \\ \text { emhyp510 } & -1.901 & -1.581 & -0.945 & -0.636 & -0.234 & 0.945 & 1.196 & \text { Stat. }\end{array}$

Network effects

$\begin{array}{lrrrrrrrr}\text { netwrk } & -0.009 & 0.058 & 0.132 & 0.263 & 0.399 & 0.205 & 0.25 & \text { Stat. } \\ \text { netw_15 } & -0.335 & -0.176 & -0.13 & -0.015 & 0.556 & 0.161 & 0.162 & \text { Stat. } \\ \text { netw_315 } & -1.367 & -0.751 & -0.086 & -0.025 & -0.013 & 0.725 & 0.192 & \text { Nonstat. } \\ \text { netw_350 } & -0.167 & -0.081 & -0.007 & 0.278 & 0.515 & 0.359 & 0.314 & \text { Nonstat. }\end{array}$

Hospital Characteristics

$\begin{array}{lrrrrrrrr}\text { hmo } & 0.208 & 0.375 & 0.461 & 0.54 & 0.709 & 0.165 & 0.286 & \text { Stat. } \\ \text { beds } & 4.70 \mathrm{E}-04 & 8.00 \mathrm{E}-04 & 0.001 & 0.002 & 0.002 & 0.001 & 0.001 & \text { Nonstat. } \\ \text { pc_mcare } & -2.872 & -2.371 & -2.328 & -2.169 & -1.631 & 0.202 & 0.58 & \text { Stat. } \\ \text { pc_mcaid } & -1.834 & -0.901 & -0.577 & -0.305 & -0.073 & 0.596 & 0.718 & \text { Stat. } \\ \text { pltpadm } & 0 & 0 & 0 & 1.00 \mathrm{E}-06 & 2.00 \mathrm{E}-06 & 1.00 \mathrm{E}-06 & 3.68 \mathrm{E}-06 & \text { Stat. } \\ \text { profit } & -0.962 & -0.648 & -0.583 & -0.548 & -0.439 & 0.01 & 0.262 & \text { Stat. }\end{array}$

Demographic Characteristics

\begin{tabular}{lrrrrrrrr} 
mhi & $-3.20 \mathrm{E}-05$ & $-1.10 \mathrm{E}-05$ & 0 & $5.00 \mathrm{E}-06$ & $7.00 \mathrm{E}-06$ & $1.60 \mathrm{E}-05$ & $8.18 \mathrm{E}-06$ & Nonstat. \\
popsqmi & $-1.00 \mathrm{E}-05$ & $-5.00 \mathrm{E}-05$ & $8.20 \mathrm{E}-05$ & $1.55 \mathrm{E}-04$ & $2.44 \mathrm{E}-06$ & $1.60 \mathrm{E}-04$ & $1.65 \mathrm{E}-05$ & Nonstat. \\
\hline \hline
\end{tabular}

\subsection{Geographically Weighted Regression Results}

Estimation results and key statistics from the Geographically Weighted Regression (GWR) model (Equation 9) can be found in Tables 4 and 5. In particular the focus is the comparison between a variable's interquartile range of variable estimates in the GWR model and the value of two times the standard error of the full non-spatial logit model. When the interquartile range exceeds two times the standard error, this relationship suggests that the parameter is nonstationary across space. As can be seen from the table, several variables are considered nonstationary. Of particular interest are those variables that are nonstationary and statistically significant. Among the market equation in Table 4, these include nphop15, nphop510, beds, pc_mcare, and popsqmi. For the integrated equation in Table 5, these include emhyp15 and beds. In each of these cases, the parameter estimates across geographic space are sufficiently heterogeneous that using a single global parameter estimate may incorrectly interpret the response of that parameter on the decision to choose a market or integrated arrangement with a physician for a given hospital in a specific geographic region.

The parameter estimates for each of the points were computed, points plotted in ArcView GIS, and a contour map constructed and shown in Figure 1. As can be seen in the figure, despite

(C) Southern Regional Science Association 2010. 


\section{Figure 1. Contour Map for npho15 Parameter Estimates (Market Equation)}

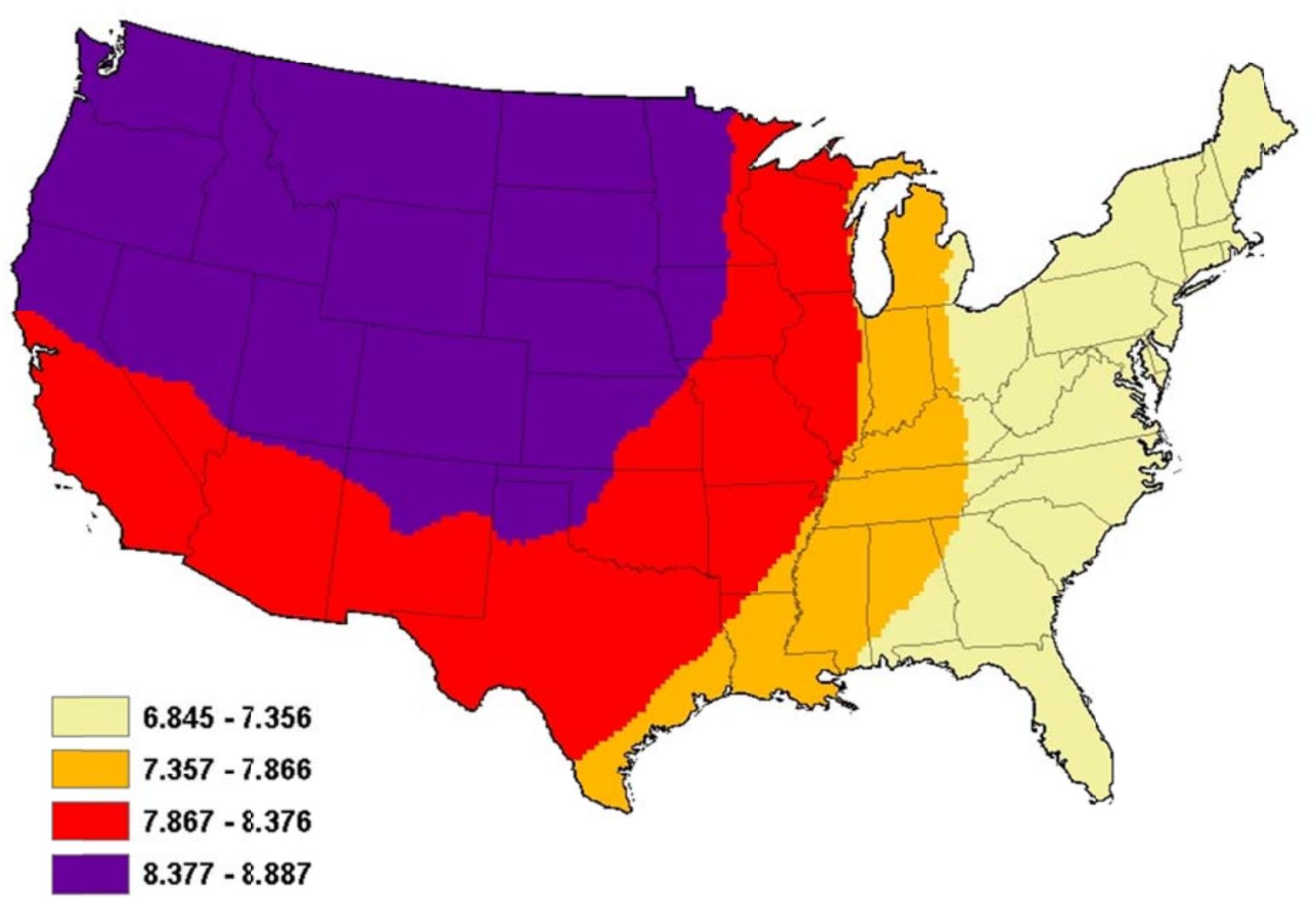

the global estimate being positive and statistically significant, there is much variation in the magnitude of the response 4 . Specifically, the impact of nearby hospitals with market arrangements on the choice of a hospital to engage in these arrangements with their physicians is much greater in the Plains, Rocky Mountains, and Northwest, than in the Middle Atlantic and New England. We also see similarities in response in the western portions of the Midwest, South and Southwest.

Another attribute of GWR modeling is the ability to identify when a variable may be significant in certain regions of the country, but not globally. This is most easily shown by the GWR estimate for nphop315 in the market equation. In the full model, this variable was not statistically different from zero. However, when evaluating the GWR results, the parameter was shown to be both nonstationary and having a collection of estimates that ranged from highly negative to highly positive. With this overlay, we are able to optimize the legend to identify those regions that had both significantly negative and significantly positive parameter estimates. The resulting contour map in Figure 2 highlights these results. 
Figure 2. Contour Map for npho315 Parameter Estimates (Market Equation)

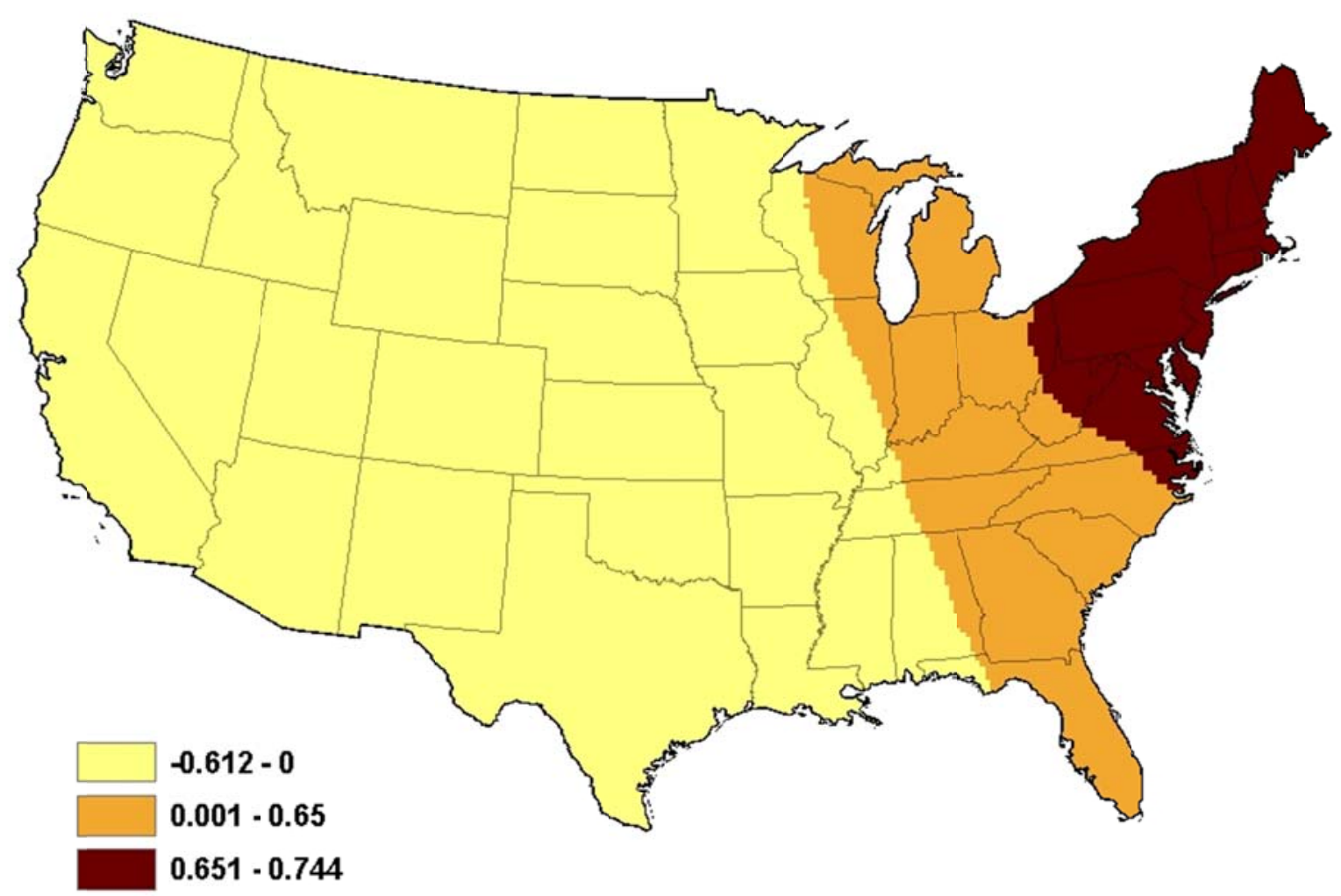

Since each separate regression in the GWR model generates individual $t$-values, we were able to test the significance of each parameter in each equation. Approximately 20 percent of all $t$-values were greater than the absolute value of two. We plotted the points of all hospitals that had parameter estimates that were significant on top of a contour map of the parameter estimates for the variable (not shown).

The dark contour representing New England/Middle-Atlantic states corresponds to the region with the largest positive response; that is, hospitals in this region are more likely to choose market physician arrangements when hospitals between 15 and 35 miles also have market physician arrangements. Based on t-statistics, over 95 percent of regressions run on the 705 hospitals in this region had a statistically significant parameter estimate for this variable. Similarly, a contour map showing the distribution of coefficient estimates for the nphop510 variable (not shown) identify a similar dichotomy between New England and the Mid-Atlantic from the rest of the country. ${ }^{5}$ While 36 percent of the remainder of the country's hospitals saw a significantly negative effect from this variable, none of the coefficients on hospitals in the New England/Mid-Atlantic region contour were significantly affected by hospitals 50 to 100 miles away. The combination of these results from the GWR models would suggest that New

\footnotetext{
${ }^{5}$ The nphop315 and npho510 New England/Mid-Atlantic region contours shared approximately 96 percent of the same hospitals.
} 
England/Mid-Atlantic region hospitals are more likely to be influenced to take on similar market physician contracts of both geographically nearby and slightly further removed hospitals.

\section{IMPLICATIONS AND EXTENSIONS OF RESEARCH}

This paper has several implications that should be noted. The first is that the attributes of an individual hospital do provide some information about what arrangement choice a hospital may enter into with a physician. Hospitals that are part of a network, participate in an HMO, and have a large number of beds are more likely to choose integrated arrangements. Hospitals that are for-profit with higher percentages of Medicare admissions and population densities are more likely to choose market arrangements with their physicians.

Second, spatial relationships do play an important factor in the choice of physician arrangements. Based on results from using spatially defined explanatory variables, the largest marginal effect of all covariates in both the market and integrated equations came from the percent of hospitals within 15 miles of a reference hospital with a specific physician arrangement. Also, the percent of hospitals between 50 and 100 miles with a specific physician arrangement actually reduced the probability that a hospital would apply a market physician arrangement.

Third, generating spatial variation by subdividing the dataset into metro and nonmetro hospitals did tease out some additional relationships and showed varying marginal effects. An increasing percentage of Medicaid patients statistically increased the probability of market physician arrangements and lowered the probability of integrated arrangements in nonmetro hospitals. Further, the marginal effect of the percent of hospitals within 15 miles with a market arrangement in nonmetro hospitals was 34 percentage points greater than the same marginal effect in metro hospitals.

One of the most interesting findings from the research came through application of the GWR model. In addition to showing nonstationary parameter estimates across space, those insignificant global parameter estimates that were evaluated as nonstationary identified significant relationships regionally. In the market equation, while it was shown that in the global logit model the percent of hospitals with a market arrangement between 15 and 35 miles had no significant effect on the probability of choosing market physician arrangements, the GWR model identified significantly positive effects of the same variable in the Northeastern United States. These results suggest that rural health care services researchers interested in confirming theoretical relationships as well as measuring policy impacts should move beyond both simple rural/urban subdivisions as well as spatially defined covariates to GWR-type models that allow for spatially distinct estimates that can identify similarities and differences of policy impacts across multiple regions of the United States.

There are a few limitations that should be noted in this research. First, as is traditional of a cross-sectional analysis, one should be careful when inferring causal relationships from this analysis. It should be noted that in many spatial econometric models with spatial lags, the spatially lagged dependent variable should not be considered as the covariate causing the variation in the dependent variable. It is likely the case that spatially varying exogenous covariates that are either unobservable or costly to measure are driving the underlying change in the spatially lagged dependent variable. Second, the research was limited in its ability to test the transaction cost hypothesis due to limited proxies for attributes of the transaction. Further review

(C) Southern Regional Science Association 2010. 
of reasonable proxies from secondary data for transaction attributes in hospital contracting should be investigated.

Future research analyzing hospital arrangements with physicians should be focused in a number of areas. First, relatively poorer performance in the integrated equation suggests that an alternative aggregation of hospital arrangements among those in the integrated category may generate increased model fit and predicted probabilities. Research that evaluates the similarities and differences of these arrangements will provide insight into an optimal aggregation scheme. Also, research should be conducted into the dynamics of how hospitals in a given region choose to use like physician arrangements. Is the process of moving hospitals to alternative physician arrangements in a given geographic area a slow or fast process? There may be some structural factors that are not quantifiable that may play into dissimilarity of contractual structures of nearby hospitals. This diffusion process may also be a function of path dependence. Hospitals are composed of a number of different physicians with differing lengths of contractual arrangements and physicians with varying lengths of tenure. Such heterogeneity may impact this lag effect in the diffusion process.

This research suggests that rural health services researchers should consider analyzing rural health policies in a larger spatial context such as GWR modeling. Performance or quality changes that occur as a result of the adoption of rural health policies may be insufficiently analyzed when analyzing a control group of rural hospitals that has not adopted a policy. Since eligibility for rural health policies such as CAH vary widely across space (some states have a very large percentage of eligible and/or converted CAH hospitals while others have very few), traditional modeling procedures may signal policy generated effects that are being generated by other non-policy factors in CAH dense regions. GWR modeling at a minimum may help rural health researchers identify dichotomies in rural health policy performance and be able to suggest targeted adjustments in these programs to better recognize the heterogeneity of these rural places.

In conclusion, this research has investigated the factors that affect the decision of a hospital to choose specific physician arrangement structures. The key outcome of this research is consistent with the findings of Ali, Partridge, and Olfert (2007)—spatial relationships matter! Both health care services researchers and regional scientists should consider using GWR models to complement their existing toolbox of spatial statistical applications.

\section{REFERENCES}

American Hospital Association. (2006) AHA Annual Survey Database FY 2004. [database on CD-ROM]. Chicago, IL: Health Forum.

Ali, KKamar, Mark D. Partridge and M. Rose Olfert. (2007) "Can Geographically Weighted Regressions Improve Regional Analysis and Policy Making?," International Regional Science Review, 30, 300-329.

Anselin, Luc. (2002) "Introduction to Spatial Analysis." Regional Economic Applications Laboratory, University of Illinois-Urbana Champaign. Last accessed on September 17, 2010 at: http://www.csiss.org/events/workshops/2002/data2002/outline.pdf.

Barnes, James N. and J. Matthew Fannin. (2006) "Vertical Integration Business Strategies in Health Care Markets: Theory and Evidence," Southern Business and Economic Journal, 29(3\&4), 69-87.

(C) Southern Regional Science Association 2010. 
Barnes, James, Harvey James and Nicholas Kalaitzandonakes, (2005) "An Application of the Coasian Lens to GMO Regulation," in Harvey James (ed.), New Ideas in Contracting and Organizational Economics Research. Nova Science Publishers: Hauppauge, NY, pp. 149-162.

Basu, Jayasree. and Lee R. Mobley. (2007) "Illness Severity and Propensity to Travel Along the Urban-Rural Continuum," Health and Place, 13, 381-399.

Charlton, Martin, Chris Brunsdon and A. Stewart Fotheringham. (2003) GWR 3: Software for Geographically Weighted Regression. Spatial Analysis Research Group, University of Newcastle: England.

Coles Jerilyn W. and William S. Hesterly. (1998) “Transaction Costs, Quality, and Economies of Scale: Examining Contracting Choices in the Hospital Industry," Journal of Corporate Finance," 4, 321-345.

Cuellar, Allison E. and Paul J. Gertler. (2006) "Strategic Integration of Hospitals and Physicians," Journal of Health Economics, 25, 1-28.

Dalton, Kathleen, Rebecca Slifkin, Stephanie Poley, and Melissa Fruhbeis. (2003) "Choosing to Covert to Critical Access Hospital Status," Health Care Financing Review, 25, 115-132.

Dynan, Linda, Gloria J. Bazzoli and Lawton R. Burns. (1998) "Assessing the Extent of Integration Achieved Through Physician-Hospital Arrangements," Journal of HealthCare Management, 43, 242-262.

Esposto, Alfredo.. (2004) "Contractual Integration of Physician and Hospital Services in the U.S.," Journal of Management and Governance, 8, 49-69.

Fannin J. Matthew and James N. Barnes. (2007) "Recruitment of Physicians to Rural America: A View through the Lens of Transaction Cost Theory," Journal of Rural Health, 23, 141149.

Florax, Raymond, Hendrik Folmer and Sergio J. Rey. (2003) "Specification Searches in Spatial Econometrics: The Relevance of Hendry's Methodology," Regional Science and Urban Economics, 33, 557-579.

Fotheringham, A. Stewart, Chris Brunsdon and Martin Charlton. (2002) Geographically Weighted Regression: The Analysis of Spatially Varying Relationships. John Wiley \& Sons: West Sussex, England.

Gresenz, Carole R., Jeannette Rogowski and Jose J. Escarce. (2004) "Updated Variable-Radius Measures of Hospital Competition,” Health Services Research, 39, 417-430.

Holmes, Mark, George H. Pink and Rebecca T. Slifkin. (2006) "Impact of Conversion to Critical Access Hospital Status on Hospital Financial Performance and Conversion," Findings Brief 1. Flex Monitoring Team, University of Minnesota, University of North CarolinaChapel Hill, and University of Southern Maine. November. Last accessed on September 17, 2010, at: http://www.flexmonitoring.org/documents/CAHFindingsBriefl.pdf.

Isserman, Andrew. (2005) "In the National Interest: Defining Rural and Urban Correctly for Research and Public Policy,” International Regional Science Review, 28, 465-499.

(C) Southern Regional Science Association 2010. 
LeSage, James and R. Kelley Pace. (2009) Introduction to Spatial Econometrics. CRC Press: Boca Raton, FL.

Mick, Stephen S. (1990) "Explaining Vertical Integration in Health Care: An Analysis and Synthesis of Transaction Cost Economics and Strategic Management Theory," in Steven S. Mick and Associates (eds.), Innovations in Health Care Delivery: Insights for Organization Theory. Jossey-Boss Inc: San Francisco, pp. 207-240.

Quality Resource Systems. 2007. Area Resource File 2006. [database on CD-ROM].

Robinson, James C. (1999) The Corporate Practice of Medicine: Competition and Innovation in Health Care. University of California Press: Los Angeles.

Rural Health Resource Center. (2008) “Flex Program,” Last accessed on September 17, 2010, at: http://www.ruralcenter.org/tasc/flex.

Stensland Jeffrey, and Thomas Stinson. (2002) "Successful Physician-Hospital Integration in Rural Areas," Medical Care, 40, 908-917.

Tai, Wan-Tzu, Frank W. Porell and E. Kathleen Adams. (2004) "Hospital Choice of Rural Medicare Beneficiaries: Patient, Hospital Attributes, and the Patient-Physician Relationship," Health Services Research, 39, 1903-1922. 


\section{APPENDIX. PHYSICIAN ARRANGEMENT DESCRIPTIONS}

\begin{tabular}{|c|c|c|}
\hline $\begin{array}{c}\text { Physician } \\
\text { Arrangement }\end{array}$ & $\begin{array}{c}\text { Dependent } \\
\text { Variable Applied } \\
\text { to In Model } \\
\end{array}$ & Description \\
\hline $\begin{array}{l}\text { Independent Practice } \\
\text { Association (IPA) }\end{array}$ & npho & $\begin{array}{l}\text { An IPA is a legal entity that holds manage care } \\
\text { contracts The IPA then contracts with physicians } \\
\text { usually in solo practice, to provide care either on a } \\
\text { fee-for-services or capitated basis. The purpose of an } \\
\text { IPA is to assist solo physicians in obtaining manage } \\
\text { care contracts. }\end{array}$ \\
\hline $\begin{array}{l}\text { Group Practice } \\
\text { Without Walls } \\
(\text { GPWW) }\end{array}$ & npho & $\begin{array}{l}\text { Hospital sponsors the formation of, or provides } \\
\text { capital to physicians to establish a "quasi" group to } \\
\text { share administrative expenses while remaining } \\
\text { independent practitioners. }\end{array}$ \\
\hline $\begin{array}{l}\text { Open Physician } \\
\text { Hospital Organization } \\
\text { (OPHO) }\end{array}$ & npho & $\begin{array}{l}\text { A joint venture between the hospital and all member } \\
\text { of the medical staff who wish to participate. The } \\
\text { PHO can act as a unified agent in managed care } \\
\text { contracting, own a managed care plan, own and } \\
\text { operate ambulatory care centers or ancillary services } \\
\text { projects, or provide administrative services to } \\
\text { physician members. }\end{array}$ \\
\hline $\begin{array}{l}\text { Close Physician- } \\
\text { Hospital Organization } \\
\text { (CPHO) }\end{array}$ & emhy & $\begin{array}{l}\text { A PHO that restricts physician membership to those } \\
\text { practitioners who meet criteria for cost effectiveness } \\
\text { and/or high quality. }\end{array}$ \\
\hline $\begin{array}{l}\text { Management Services } \\
\text { Organization (MSO) }\end{array}$ & emhy & $\begin{array}{l}\text { A corporation, owned by the hospital or a } \\
\text { physician/hospital joint venture, that provides } \\
\text { management services to one or more medical group } \\
\text { practices. The MSO purchases the tangible assets of } \\
\text { the practices and leases them back as part of a full- } \\
\text { service management agreement, under which the } \\
\text { MSO employs all non-physician staff and provides } \\
\text { all supplies/administrative systems for a fee. }\end{array}$ \\
\hline $\begin{array}{l}\text { Integrated Salary } \\
\text { Model (ISM) }\end{array}$ & emhy & $\begin{array}{l}\text { Physicians are salaried by the hospital or another } \\
\text { entity of a health system to provide medical services } \\
\text { for primary care and specialty care. }\end{array}$ \\
\hline Equity Model & emhy & $\begin{array}{l}\text { Allows established practitioners to become } \\
\text { shareholders in a professional corporation in } \\
\text { exchange for tangible and intangible assets of their } \\
\text { existing practices }\end{array}$ \\
\hline Foundation & emhy & $\begin{array}{l}\text { A corporation, organized either as a hospital affiliate } \\
\text { or subsidiary, which purchases both the tangible and } \\
\text { intangible assets of one or more medical group } \\
\text { practices. Physicians remain in a separate corporate } \\
\text { entity but sign a professional services agreement } \\
\text { with the foundation. }\end{array}$ \\
\hline No Arrangement & npho & $\begin{array}{l}\text { An individual that answered having zero physicians } \\
\text { as a part of any of the physician arrangements listed. }\end{array}$ \\
\hline
\end{tabular}

